\title{
Incentive value of saccharin as a function of concentration and deprivation conditions'
}

\author{
ROY WEINSTOCK, RICHARD T. WHITE ${ }^{3}$ AND ROBERT C. BOLLES \\ HOLLINS COLLEGE
}

\begin{abstract}
Abstraet
Rats, either hungry, thirsty or satiated, pressed a bar for $1 \mathrm{hr}$. on a FR10 schedule for $0.0,0.08,0.31,1.23$ and $5.03 \%$ saccharin solutions. Performance vs. concentration functions were of similar shape for hungry, thirsty and satiated Ss, although the thirsty Ss performed at a higher level than the others.

Problem
\end{abstract}

It has been found that the incentive value of saccharin for rats varies with concentration, the highest incentive value most commonly reported from a variety of test situations lying near 0.5\% (Bacon et al, 1962; BeebeCenter et al, 1948; Cockrell, 1952; Hughes, 1957). Other experimenters (Hulse \& Bacon, 1962; Collier, 1962) have reported performance increasing monotonically with concentration up to $1 \%$ or higher, under certain conditions. In some of these studies, however, it is not clear how the deprivation conditions should be interpreted. Thus, Beebe-Center's Ss were ad lib so that we cannot tell if their saccharin consumption indicates hunger, thirst, or any deprivation at all. Similar uncertainty pertains to the Hulse \& Bacon study where Ss were deprived of both food and water.

The only systematic comparisons of deprivation conditions in this context are the studies by (1) Bacon et al, who found that hungry and satiated Ss yielded similar intake vs. concentration functions, and (2) Collier, who reported comparable functions for hungry and thirsty Ss for large reinforcements $(0.3 \mathrm{ml})$, but different functions for small reinforcements $(<0.1 \mathrm{ml})$. In both of these studies hungry Ss showed a somewhat greater consumption of the higher saccharin concentrations than Ss under other deprivation conditions. In the present study, performance vs. concentration functions are described for hungry, thirsty and satiated Ss all tested in the same bar-pressing situation.

Method

The Ss were six male and six female Sprague-Dawley rats about 120 days old. The test apparatus was a Skinner box equipped with a motor driven water dipper which presented $.15 \mathrm{ml}$ of solution for $3 \mathrm{sec}$. as reinforcement. In $3 \mathrm{sec}$. the ratordinarily drinks only about $.08 \mathrm{ml}$, so that ingestion per reinforcement was limited to that amount. Saccharin solutions, 0.0, 0.08, 0.31, 1.23 and $5.03 \%$ by weight, were prepared after each day's running was completed, and stored in air-tight jars at room temperature for use the following day. Particular care was taken to wash out the dipper, the water trough and the box between different test solutions.
Throughout testing four Ss were hungry, i.e., reduced to $80 \%$ of initial body weight, four Ss were $23 \mathrm{hr}$. waterdeprived, and four were ad lib food and water. The behavior of one satiated $S$ broke down during the course of testing, his data were discarded, and so only three Ss are represented in the satiated group. Prior to testing Ss were shaped up to press the bar and trained on increasing FR schedules until stable FR10 behavior was established. It is important to note that the typical hungry and satiated Ss could not be shaped directly with saccharin reinforcement. Some Ss refused to drink saccharin when it was available; others would drink it but would not press the bar for it. We found it necessary to establish the behavior first under thirst, using $0.31 \%$ saccharin, and then after three or four sessions when FR10 behavior was well established switch Ss to the deprivation conditions under which they were to be tested. When the behavior had been established with $0.31 \%$ saccharin under the relevant deprivation conditions Ss were tested either with the sequence 0.31 , $1.23,50.3,0.00,0.08$ and $0.31 \%$, or with the reverse sequence. Finally, all Ss were run through a second cycle of concentrations, with either the same sequence they had before or with the reverse sequence. All test sessions were $1 \mathrm{hr}$.

\section{Results}

Figure 1 shows the mean number of responses per session as a function of saccharin concentration and deprivation conditions. Cumulative records of bar pressing indicated that there were some differences in style of responding and in the distribution of responses during the the test hour, however, none of these secondary effects obscured the overall dependence of performance upon saccharin concentration. The performance over the whole hour, shown in Fig. 1, is reasonably representative of performance at each point of the test hour. Specifically, there was in all cases a marked drop-off in responding with the highest concentration solution even during the first $10 \mathrm{~min}$. of testing.

An analysis of variance of responding for the $0.31 \%$ solution indicated that there were highly significant individual differences relative to the within-subject variability, and that there were significant differences between deprivation conditions relative to the individual differences. Thus, thirsty Ss not only were much superior in the acquisition of bar pressing, they responded at a higher rate at this concentration than hungry and satiated Ss. 


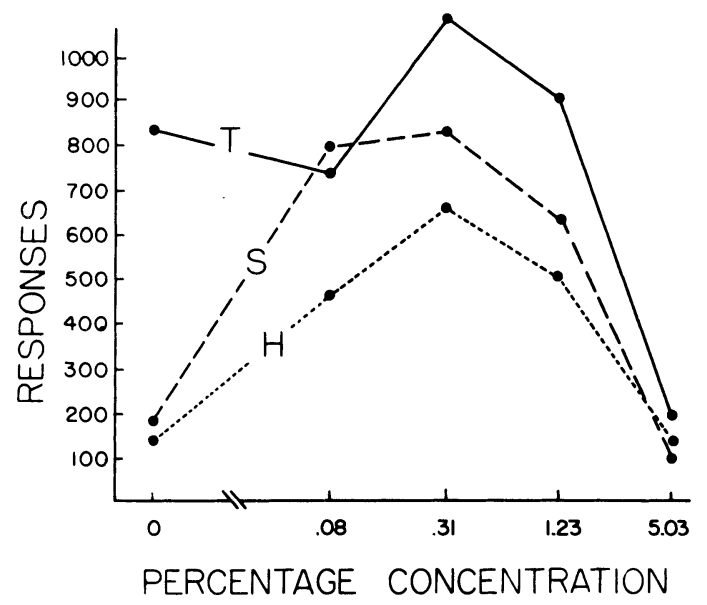

Fig. 1. Bar presses in a 1-hr. session for different concentrations of saccharin by hungry, thirsty and satiated Ss.

\section{Discussion}

The most noteworthy feature of these results is the similarity of the performance vs. concentration functions of hungry, thirsty and satiated Ss (except at the $0.0 \%$ concentration where thirsty Ss responded much more than the others). Whereas Collier (1962) has reported that the shape of these functions depends upon the amount of reinforcement, so that the incentive value of saccharin can be a quite complex function of concentration, our results show that this relationship can also be quite simple, and relatively independent of deprivation conditions. Our results are inconsistent with Collier's for the case of hungry Ss with comparable amounts of reinforcement. With $.1 \mathrm{ml}$ reinforcements he found a monotonic rise in performance with concentration to $2.5 \%$. This discrepancy may be due to the fact that his Ss were on a FI schedule whereas our Ss were on a FR schedule. But probably a more important methodological difference is that Collier's Ss had much more experience with each solution before being tested on it than ours did. Hulse \& Bacon, who also gave their Ss considerable training with each solution prior to testing, found monotonic increases, independently of the reinforcement schedule, to $1 \%$ solutions which was the highest concentration they used. Hence our results may only be applicable to the case of Ss tested with constantly varying concentrations.

\section{References}

Bacon, W. E., Snyder, H. L., \& Hulse, S. H. Saccharine preference in satiated and deprived rats. J. comp. physiol. Psychol., 1962, $55,112-114$

Beebe-Center, J. G., Black, P., Hoffman, A. C., \& Wade, M Relative per diem consumption as a measure of preference in the rat. J. comp. physiol. Psychol., 1948, 41, 239-251.

Cockrell, J. T. Operant behavior in relation to the concentration of a nonnutritive sweet substance used as a reinforcement. Unpublished Ph. D. dissertation, Indiana University, 1952.

Collier, G. Some properties of saccharin as a reinforcer. J. exp. Psychol., 1962, 64, 184-191.

Hughes, L. H. Saccharin reinforcement in a $\mathrm{T}$ maze. J. comp. physiol. Psychol., 1957, 50, 431-435.

Hulse, S. H., \& Bacon, W. E. Supplementary report: partial reinforcement and amount of reinforcement as determinants of instrumental licking rates. J. exp. Psychol., 1962, 63, 214-215.

\section{Notes}

1. This study was supported by Research Grant GB-1650 from the National Science Foundation.

2. Now at Syracuse University.

3. Now at University of Rochester. trarily continued until the pre-shift effects on running speed were no longer present.

2. Consummatory rate in Group 400-20 remained constant throughout the post-shift period whereas instrumental performance gradually declined, but if one were determined by the other then both should have followed the same course. In fact on the last post-shift trial the pre-shift experimental treatment accounted for $30 \%$ of the variance in drinking rate in Groups 400-20 and 20-3, which is the same as obtained in the pre-shift phase when the first 20 licks are considered. Thus licking rate is unchanged by the shift-an important finding, but not because of any supposed implications of unchanged functional reinforcement.

3 . Proportions of variance accounted for by the experimental treatments in these two groups were calculated for pre-shift trial 42, the last trial of the final pre-shift day. The experimental treatment accounted for $78 \%$ of the variance in running speed, for $0 \%$ of the variance in total drinking speed, and for $30 \%$ of the variance in drinking speed over the first 20 licks. (This last was not available in the reported study and comes from similar groups in a larger study which in part replicated this one.) That the correlation between treatment and running is by far the highest would hardly be anticipated if the treatment condition affected instrumental behavior only indirectly through the mediation of its effect on consummatory behavior. This leads us to reject the hypothesis that instrumental behavior in the pre-shift phase was determined by consummatory rate, and we feel that reviving the hypothesis for the post-shift phase of the experiment would be a cavalier theoretical treatment of an important empirical finding.

James R. Ison and Alexander J. Rosen University of Rochester

(For comment by James Allison, see page 92) 